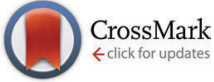

Cite this: J. Mater. Chem. C, 2016 4, 5879

\title{
Switchable colloids, thin-films and interphases based on metal complexes with non-innocent ligands: the case of valence tautomerism and their applications
}

\author{
N. A. Vázquez-Mera, ${ }^{\text {ab }}$ F. Novio, ${ }^{a}$ C. Roscini, ${ }^{a}$ Ch. Bellacanzone, ${ }^{a}$ M. Guardingo, ${ }^{a}$ \\ J. Hernando ${ }^{b}$ and D. Ruiz-Molina*a
}

Received 5th January 2016,

Accepted 27th April 2016

DOI: $10.1039 / c 6 t c 00038 j$

www.rsc.org/MaterialsC

\begin{abstract}
Successful nanostructuration approaches developed in the last few years have allowed the preparation of robust valence tautomeric (VT) switchable (micro-/nano-) structures of a variety of dimensions and morphologies. These results are expected to definitely foster the implementation of these materials on hybrid molecular electronic devices but also endorse new applications in other different fields such as sensing, drug delivery or water remediation, among others.
\end{abstract}

\section{Introduction}

The term "non-innocent ligand", firstly pointed out by Jørgensen, ${ }^{1}$ is directly related to the role and the influence of certain ligands on the electronic distribution of transition metal complexes. This is the case of valence tautomeric (VT) complexes that

\footnotetext{
${ }^{a}$ Catalan Institute of Nanoscience and Nanotechnology (ICN2), CSIC and The Barcelona Institute of Science and Technology, Campus UAB, Bellaterra, 08193 Barcelona, Spain. E-mail: dani.ruiz@icn2.cat

${ }^{b}$ Departament de Química, Universitat Autònoma de Barcelona (UAB), Campus UAB, Cerdanyola del Vallès, 08193 Spain
}

combine transition metal ions, having two or more accessible oxidation states, with redox-active ligands. ${ }^{2}$ Charge distribution in these electronically labile complexes has an appreciable sensitivity to the environment. As such, the application of an external perturbation, like photons, pressure or, mainly, temperature, may lead to an intramolecular electron transfer between both redox active units and, therefore, to a reversible interconversion between two degenerated electronic states. ${ }^{3}$ A representative example of a VT interconversion involving such an electronic redistribution is shown in Scheme 1.

Since each electronic isomer exhibits different colours and/or magnetic properties, these complexes have been suggested as

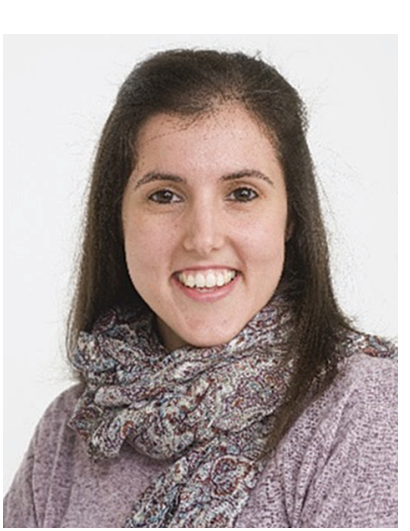

N. A. Vázquez-Mera
Nuria Alexandra Vázquez-Mera was born in Vigo in 1985. She studied Chemistry at the Universidade de Vigo where she received her BSC in 2008. She completed her PhD in Materials Science in 2015 at the Universitat Autònoma de Barcelona under the supervision of Dr Jordi Hernando and Dr Daniel Ruiz-Molina. Her PhD thesis involved the fabrication of photofunctional solid materials based on the encapsulation of stimuli-responsive systems inside liquid-filled polymeric capsules, aiming at the direct transfer of their chromic properties from solution to the solid state and the development of fast-responsive photoprotrective coatings, solid thermochromic materials and white-light color-tunable emissive systems.

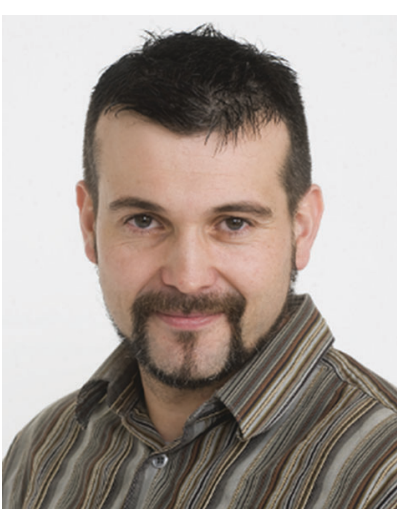

F. Novio
Fernando Novio received his PhD in chemistry (2007) from the Universitat Autonoma de Barcelona (Spain). After a postdoctoral position in the Laboratoire de Chimie de Coordination at the Univertitè Paul Sabatier (Toulouse, France) working on surface chemistry of metal nanoparticles, he moved in 2011 to the Institut Català de Nanociència I Nanotecnologia (Barcelona, Spain) as a senior researcher in the Nanostructured Functional Materials group led by D. Ruiz-Molina. He has initiated different research studies related to the technological and biomedical application of coordination polymer nanoparticles. 


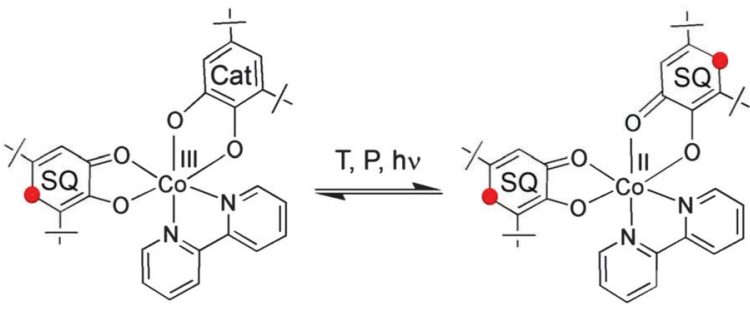

Scheme 1 Schematic representation of a typical catechol-based cobalt complex exhibiting VT and the corresponding electronic redistribution induced upon application of an external stimulus. For this a reversible intramolecular electron transfer between the metal and the redox-active ligand takes place.

candidates for future use in devices. ${ }^{4}$ Therefore, the development of robust micro-/nanoscale structures showing VT interconversion at room temperature that could be easily handled and integrated in solid materials without compromising their functionality has become a subject of major interest since the first report on valence tautomerism back in the $80 \mathrm{~s}^{5}$

Here we review all the different successful approaches so far tested with this aim. The VT nanostructured systems obtained to date exhibit switchable behaviour independent of their dimensions - from macro to micro-/nanoscale - and morphologies - from thin-films to nanoparticles and nanoimprinted motifs. In some specific cases, small hysteresis effects or the possibility of inducing an irreversible hysteresis, reminiscent of a non-volatile memory, by synchronisation with a polymer phase transition, have been reported over different polymeric matrices and other related platforms. Finally, it is worth mentioning that novel applications have recently been envisioned for this family of materials that go beyond their use in

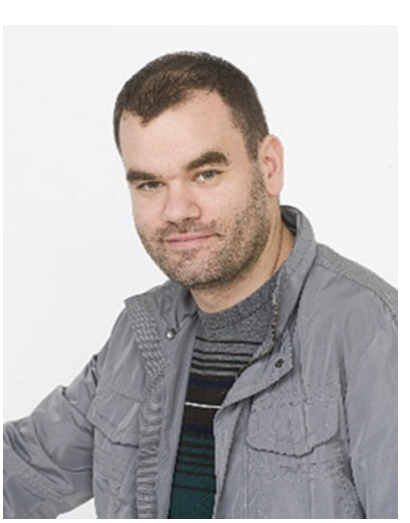

C. Roscini
Claudio Roscini obtained his PhD in chemistry in 2010 at the Bristol University (UK). Afterwards he worked at the Autonomous University of Barcelona as postdoc and successively at the Technology Institute Fundació Privada ASCAMM (Barcelona). In 2013 he joined the Nanostructured Functional Materials group at the Catalan Institute of Nanoscience and Nanotechnology (ICN2) where he is mostly involved in industrial research projects related to the optimization of encapsulation processes and to the development of new chromic systems. In June 2014 he became the co-funder of a spinoff company, Futurechromes S. L., aimed to obtain photochromic materials with enhanced performances.

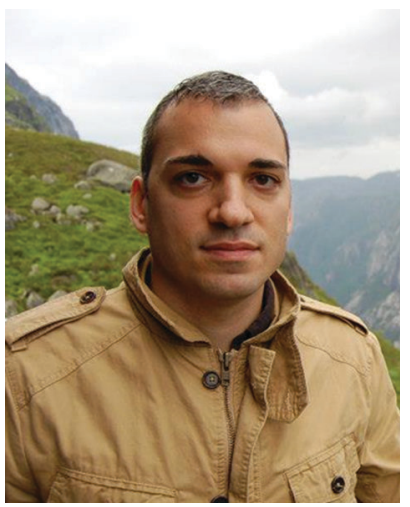

Ch. Bellacanzone

Christian Bellacanzone was born in Narni (Italy). He received his $B S c$ degree in Chemical and Industrial Biotechnology in 2011 at the University of Perugia. In 2013 he obtained his MSc degree in Molecular and Industrial Biotechnology with the work "Film formation of CdSe QDs by Dip Coating" carried out in the department of Physical Chemistry at Karlstad University (Sweden). Since 2014 he is pursuing his $\mathrm{PhD}$ in Materials Science at the Catalan Institute of Nanoscience and Nanotechnology (ICN2) under the supervision of Dr Daniel Ruiz Molina. His research focuses on the nanostructuration of conductive polymers.

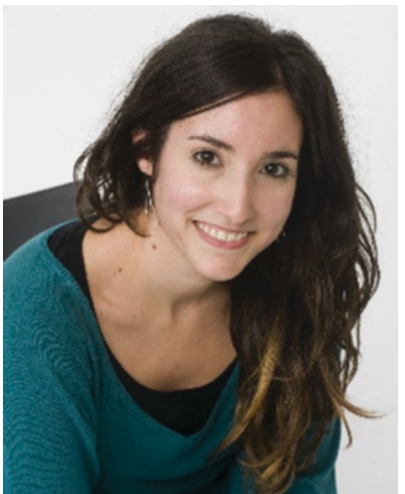

M. Guardingo
Mireia Guardingo was born in Barcelona in 1988 and she received her BSc in Chemistry in 2010 from the Universitat Autònoma de Barcelona. In 2015 she completed her PhD in Chemistry under the supervision of Dr Félix Busqué and Dr Daniel RuizMolina. Her research focused on the obtention of nanoscale catecholbased systems and the study of their properties, including the synthesis of catechol derivatives, the formation of catechol-functionalized selfassembled monolayers and gold nanoparticles and the confined synthesis of valence-tautomeric coordination polymer particles.

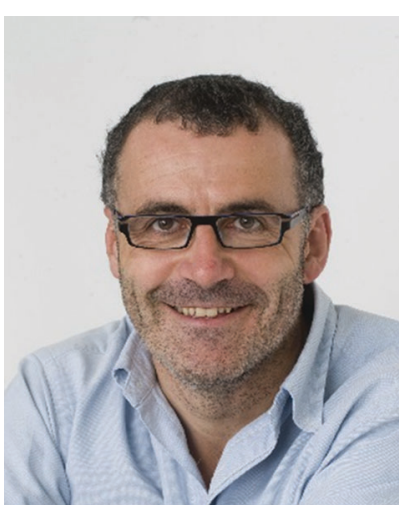

D. Ruiz-Molina
Daniel Ruiz-Molina got his PhD on polyradical dendrimers at the Institute of Materials Science of Barcelona (ICMAB). Afterwards he took a postdoctoral position at the UC San Diego working on single-molecule magnets and molecular switches for three years. In 2001 he got a permanent position at the CSIC. More recently he moved to the new Institut Catala de Nanociencia I Nanotecnologia (ICN2) where he is leading the Nanostructured Functional Materials group. His main research areas are the fabrication of hybrid colloids and surfaces, biomimetic functional nanostructures, coordination polymers and micro-/nanoparticles for smart applications and encapsulation/delivery systems. 
molecular-based electronic devices (e.g. in bioenvironmental devices and sensors). Accordingly, these new applications will also be reviewed herein.

\section{Challenge}

VT complexes exhibit localised electronic structures, low orbital mixing, and a small energy difference between their two electronic tautomers. In other words, two conditions are simultaneously satisfied: (I) the degree of covalency of the interaction between the metal ion and the electroactive ligand is low and (II) the energy of their frontier orbitals is similar. ${ }^{6}$ Both requirements have been shown to be chemically tuneable by key features intrinsic to the molecular structure of the complex, such as metal and ligand nature, ${ }^{7}$ steric hindrance, ${ }^{8}$ donor/acceptor abilities of the ancillary ligands ${ }^{9}$ and/or the volume and columbic interactions of the counterion..$^{10}$ However, all this molecular information ${ }^{11}$ turns out to be insufficient for the design of VT micro-/nanostructures that appropriately integrate on functional devices, since their switchable interconversion does not only depend on the chemical composition but also on their supramolecular packing and matrix interactions. ${ }^{12}$

The reason for such dependence lies in the entropy-driven origin of VT, as can be easily understood using the example given in Scheme $1 .^{13}$ In such a system, the low spin $\mathrm{Co}(\mathrm{III})$ isomer (ls-Co(III)) is enthalpically favoured; however, the entropy variation for the formation of the high spin Co(II) isomer (hs-Co(II)) is positive since it exhibits: (I) higher spin state degeneracy and (II) the larger density of vibrational states as a result of its longer metal-to-ligand bond length. At low temperatures, this entropic term is negligible compared to the enthalpy contribution and only the ls-Co(III) state is populated $(\Delta G>0)$. Upon warming, however, the increasingly larger effect of the entropic $T \Delta \mathrm{S}$ term makes the population of the hs-Co(II) state systematically increase up to a temperature where it becomes the most stable and, therefore, the most populated electronic isomer of the complex. ${ }^{14}$

Considering that a remarkable metal-to-ligand bond length variation takes place along the VT interconversion, matrix effects and/or crystal packing variations are therefore expected to modify $\Delta S$, and accordingly, VT interconversion. ${ }^{15}$ For instance, VT of a cobalt-based coordination polymer is determined by the crystalline phase, i.e. crystal packing, whereas neither the morphology of the crystals nor their size have a remarkable influence. ${ }^{16}$ In fact, while most VT complexes undergo thermally induced interconversion in solution, the number of examples displaying valence tautomerism in the solid state is rather limited. ${ }^{17}$ Even in those few cases, the transition temperatures have been found to be very sensitive to different factors such as the intercalation of solvent molecules within the crystalline network ${ }^{18}$ or the glass transition $\left(T_{\mathrm{g}}\right)$ of the matrix where they are dispersed. ${ }^{19}$ Such critical environmental dependence leads to an overwhelming lack of reproducibility upon enclosure of a given VT complex on different media, i.e. when transferring it from solution to a crystalline material, a polymeric composite or a self-assembled monolayer, which makes almost impossible any $a$ priori chemical design that fully ensures the success of the device. Therefore, scientists working in this field have been forced to let one's imagination run wild and design new approaches, as described next.

\section{Colloids}

\subsection{Nanoscale coordination polymer particles}

The fast precipitation of coordination polymers, initially described by Mirkin $e t$ al. ${ }^{20}$ has been successfully used for the structuration of VT units into functional amorphous nanoscale coordination polymer particles (CPPs). The first example described was based on electroactive [Co ${ }^{\mathrm{III}}(3,5$-DBSQ)(3,5-DBCat)] units, where 3,5-DBSQ and 3,5-DBCat are the semiquinonate and catecholate forms of the 3,5-di-tert-butylcatechol group, respectively, which were linked together by a bisimidazole ligand (1,4-bis(imidazol-1ylmethyl)benzene, bix). ${ }^{21}$ The bix ligand was crucial for both the polymerisation process and the subsequent formation of amorphous round-shaped nanoparticles. In fact, if bix was replaced by a more rigid ligand such as bipyridine (byp), polymerisation resulted in the formation of a crystalline material. Moreover, size control of the amorphous nanoparticles formed over the scale range of a few tens of nanometres to a few microns was achieved by tuning parameters such as reactant concentration, speed of reactant addition, or solvent nature, among others (Fig. 1a). The temperaturevariable magnetisation curve measured for these nanoparticles showed a $\chi T$ value between 2.0 and $2.5 \mathrm{emu} \mathrm{K} \mathrm{mol}{ }^{-1}$ in the $320-$ $340 \mathrm{~K}$ temperature range, which lies close to the expected value for the hs-Co(II) isomer (Fig. 1b). Upon cooling, a decrease of the temperature down to $270 \mathrm{~K}$ resulted in a relatively abrupt decrease of the $\chi T$ value down to $1.4 \mathrm{emu} \mathrm{K} \mathrm{mol}{ }^{-1}$, which was associated with a valence tautomeric interconversion from the hs-Co(II) to the ls- $\mathrm{Co}(\mathrm{III})$ isomer for a fraction of molecules in the particles.

Below this temperature, the $\chi T$ value further monotonically decreased down to $0.6 \mathrm{emu} \mathrm{K} \mathrm{mol}{ }^{-1}$ at $5 \mathrm{~K}$. This gradual decrease for most of the VT coordination polymer particles has been tentatively attributed to: (I) the interconversion from the remaining fraction of hs-Co(II) isomers to ls-Co(III) isomers, (II) spin-orbit coupling effects, and/or in less degree, (III) the presence of an additional structural transition. Another common feature of these micro-/nanostructured systems is that their magnetic properties are not size-dependent and similar temperature dependences of their magnetisation curves were measured for nanoparticles of equivalent composition but different diameters.

Different experimental approaches have been reported to modify the VT interconversion of the nanoscale coordination particles by chemical means. For this, both the polymerising ligand and/or the non-innocent catechol ligands were systematically modified. In a forerunner effort, our group has recently reported the synthesis of a novel bifunctional ligand combining a catechol and a pyridine moiety, so that both electroactive and polymerising capabilities are simultaneously present in a single unit. ${ }^{22}$ The reaction of this ligand with a Co(II) salt led to the polymerisation and fast precipitation of amorphous roundshaped nanoparticles of a few hundred nanometres in width 
(a)
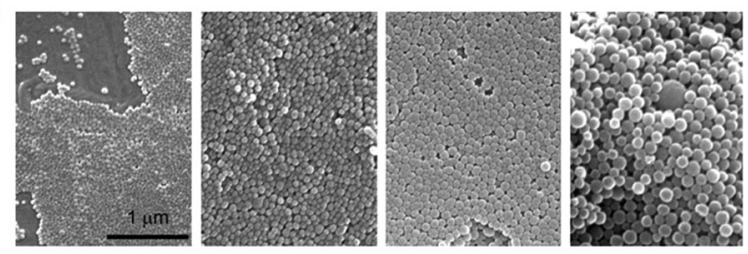

(b)

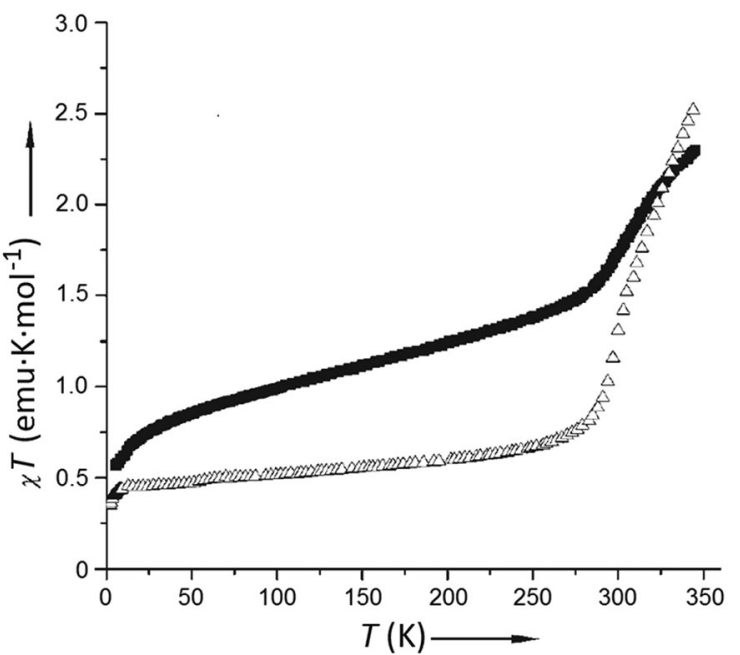

Fig. 1 (a) SEM images of colloidal spheres of [Co(Bix)(3,5-DBSQ)(3,5-DBCat)] CPPs with different average diameters controlled by experimental parameters (the $1 \mu \mathrm{m}$ scale bar is the same for all images). (b) $\chi^{T}$ values as a function of temperature for the amorphous (black squares) and crystalline (triangles) coordination polymers. Extracted from ref. 21.

(Fig. 2a). Magnetisation measurements evidenced that these nanoparticles exhibited a gradual VT interconversion in the $35-370 \mathrm{~K}$ temperature range and, more importantly, that they displayed a small hysteresis effect between the heating and cooling cycles (Fig. 2b). No clear explanation has yet been given for the occurrence of such hysteresis, which could be ascribed to different effects (e.g. cooperativity, phase change, solvent loss).

pH-sensitive materials. pH-Sensitive amorphous CPPs with average diameters between 0.2 and $1.6 \mu \mathrm{m}$ and ligand centred responses have been reported by using a flexible bis-catecholate bridging ligand..$^{23}$ In these materials, the presence of two catechol units within the same ligand ensures polymerisation and the formation of the nanoparticles as well as VT behaviour, while the $\mathrm{pH}$-triggered response is endorsed by introducing a sensitive imine bridge as a linker of the two catechol units (Fig. 3a and b). After 3 hours at $\mathrm{pH} \sim 5$, these nanoparticles showed a remarkable loss of their spherical shape and aggregation, which was associated with the acid-catalysed hydrolysis of the imine group. In contrast, the characteristic spherical shape was maintained upon incubation at $\mathrm{pH} \sim 7$ even for 14 hours. Interestingly, the morphological timedependence observed at $\mathrm{pH} \sim 5$ could be monitored by following the temperature-dependent magnetisation of the nanoparticles (Fig. 3c). However, this pH response was found to be very slow (few hours) and irreversible, thus hindering the application of these materials as magnetic pH sensors.

Drug delivery. VT interconversion has also been used ${ }^{24}$ as an internal probe to study guest encapsulation and release (a)
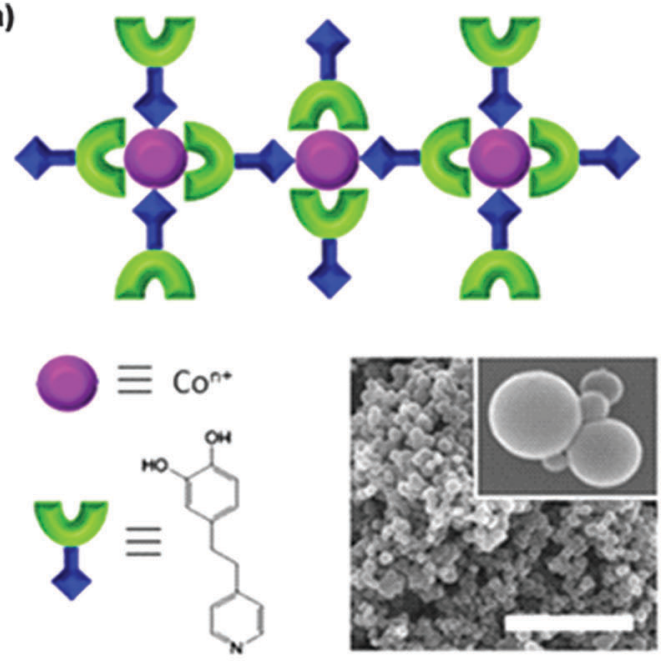

(b)

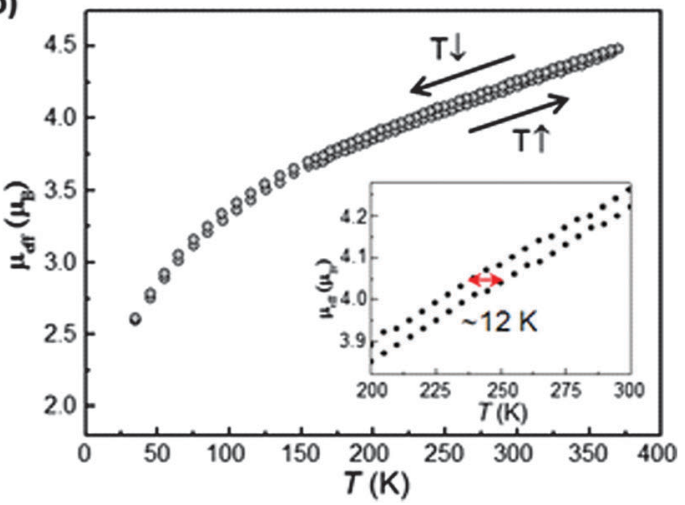

Fig. 2 (a) Formation of VT cobalt-based coordination polymers from a single ligand presenting both catechol and pyridine moieties. SEM images are shown to illustrate the morphology of the Co-CPPs obtained in this way (bar $=10 \mu \mathrm{m})$. (b) Variable temperature magnetisation measurements in the 35-370 $\mathrm{K}$ temperature range for these nanoparticles. Inset: Difference in the measured $\mu_{\text {eff }}$ when heating (bottom line) and cooling (upper line) the CPPs. Adapted from ref. 22.

mechanisms in nanoscale metal-organic drug carriers. ${ }^{25}$ For this two rationally-designed molecular guests with a red-fluorescent benzophenoxazine dye covalently tethered to a coordinating catechol group were synthesised and loaded into compositionally and structurally equivalent cobalt-based coordination polymer particles through distinct mechanisms (Fig. 4a): (I) binding to the polymer framework as a CPP building block for the unprotected catechol ligand and (II) the physical entrapment of the guest for the protected one, for which the coordinating capabilities of the catechol group were truncated. Accordingly, the two types of particles delivered their fluorescent cargo with remarkably different kinetic profiles (Fig. 4b). The extremely similar magnetic behaviour, i.e. VT interconversion, encountered for all these nanoparticles was used to identify that both families of CPPs had to be formed by equivalent coordination polymers in rather comparable phases, thus discarding any structural defect as the origin of their differential drug release behaviour.

Oil removal and water remediation. Hydrophobic VT nanoparticles that can act as a sponge to effectively separate oil 
(a)

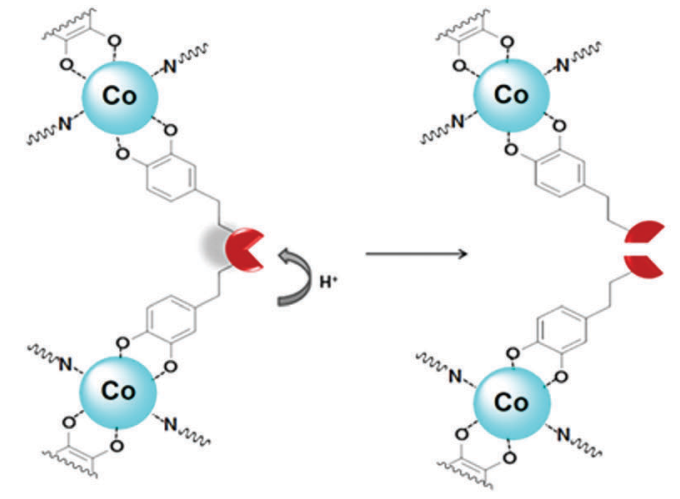

(b)

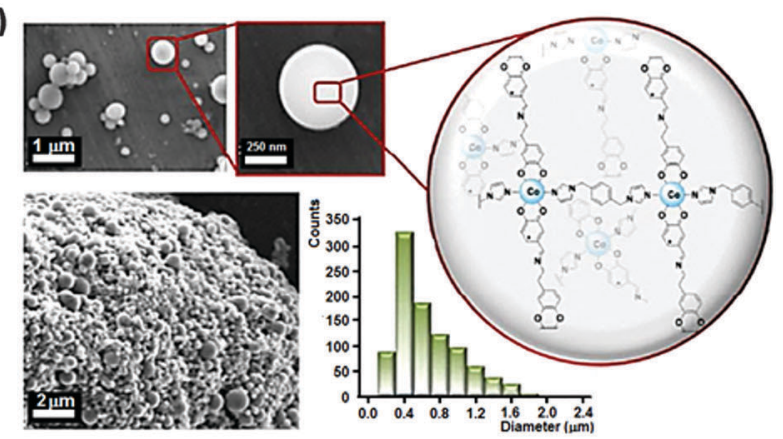

(c)

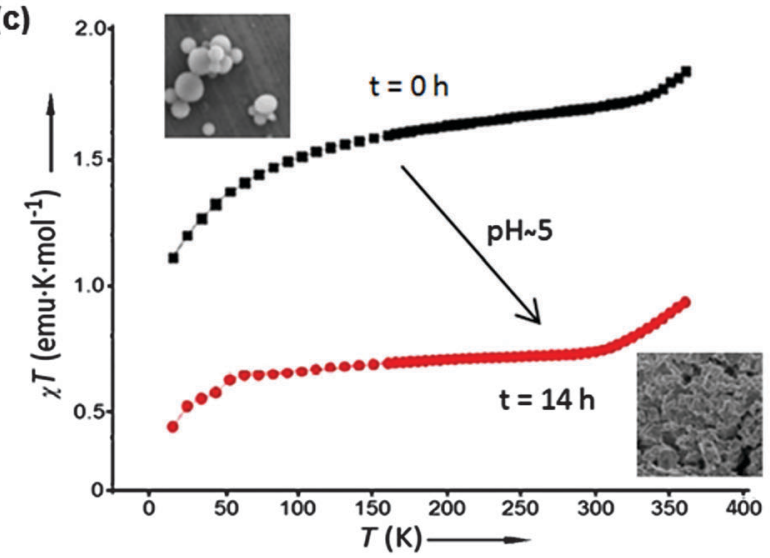

Fig. 3 (a) Schematic of the coordination polymer containing a $\mathrm{pH}$ sensitive functional group. (b) SEM images and size histogram of the $\mathrm{pH}$ sensitive CPPs prepared. (c) $\chi^{T}$ values as a function of temperature for the $\mathrm{pH}$ sensitive CPPs before and after acidic treatment for $14 \mathrm{~h}$. The insets show the SEM images of CPPs before and after decomposition at $\mathrm{pH} 5$. Figures $b$ and $c$ adapted from ref. 23.

spills from water through simple soaking or filtration processes have been reported (Fig. 5a). ${ }^{26}$ The VT properties observed by magnetisation measurements were used to confirm that the CPPs were formed structurally by similar coordination polymers in rather different phases or environments (Fig. 5b).

\subsection{Physical encapsulation in polymeric micro-/nanoparticles}

In our group we also attempted the physical entrapment within polymeric micro-/nanoparticles of the [Co $\left.{ }^{\text {III }}(\mathrm{Cat}-\mathrm{N}-\mathrm{BQ})(\mathrm{Cat}-\mathrm{N}-\mathrm{SQ})\right]$ complex, which thermally interconverts between its $\mathrm{Co}(\mathrm{III})$ and (a)
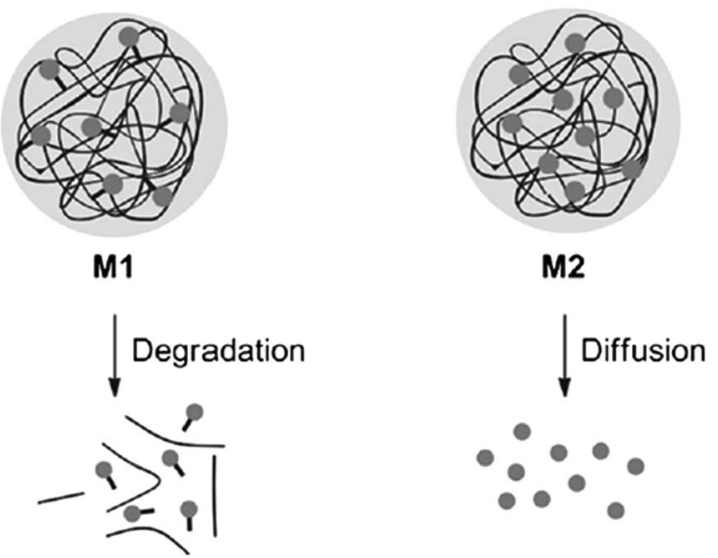

(b)

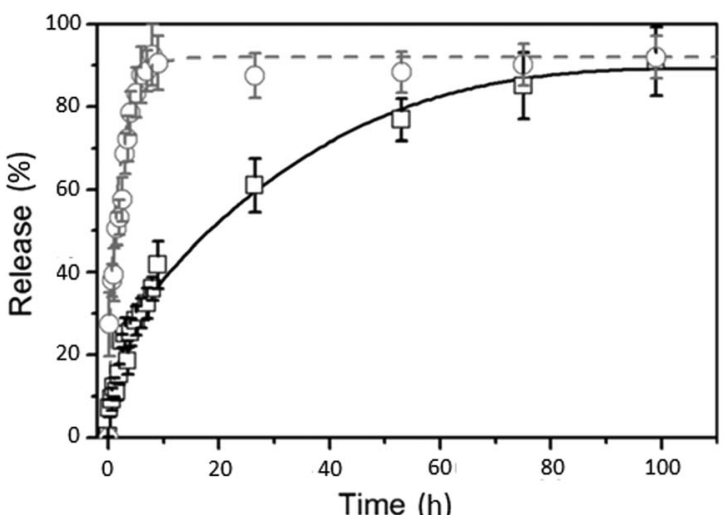

Fig. 4 (a) Schematic of the two different approaches to integrate a guest molecule into CPPs: covalently tethered to metal centres (M1) or physically entrapped into the metal-organic polymeric matrix (M2). (b) Guest release profiles of guest molecules from M1 (squares) and M2 (circles) at $37^{\circ} \mathrm{C}$. Figures reproduced from ref. 24.

$\mathrm{Co}(\mathrm{II})$ isomers by an intramolecular oxidation of the radical dianionic form of its bisiminocatechol ligand ((Cat-N-SQ $\left.)^{\cdot 2-}\right)$ to the corresponding monoanionic species (Cat-N-BQ) ${ }^{-}$(Fig. 6a). ${ }^{27}$ By means of a solvent evaporation method, this complex was encapsulated within PMMA microparticles ranging from a few microns to hundreds of nanometres in diameter (Fig. 6b). Magnetisation data in the $250-350 \mathrm{~K}$ temperature range under an external applied magnetic field of $1 \mathrm{~T}$ confirmed the maintenance of the switchable behaviour. At low temperatures, $\chi T$ was $0.4 \mathrm{emu} \mathrm{K} \mathrm{mol}^{-1}$ in agreement with the dominance of the low-spin isomer ls-Co(III) bearing one unpaired electron. This value remained approximately constant up to $300 \mathrm{~K}$, whereupon a gradual increase of the magnetic moment up to a $\chi T$ value of $0.8 \mathrm{emu} \mathrm{K} \mathrm{mol}{ }^{-1}$ at $350 \mathrm{~K}$ was observed, which is associated with the incomplete interconversion of the ls-Co(III) to the hs-Co(II) isomer. Such temperature-induced reversible interconversion was also followed by a particle colour change under an optical microscope, as qualitatively shown in Fig. 6 c $^{28}$

Encapsulation of VT complexes within organic polymers profits from the strong knowledge previously generated over years in the field of encapsulation, while CPP nanoparticles are less known. However, it must be noted that the amount of signal per nanoparticle is much larger in CPPs, as the density of 
(a)

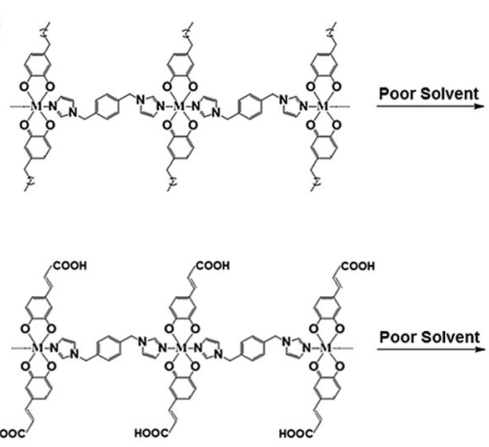

(b)

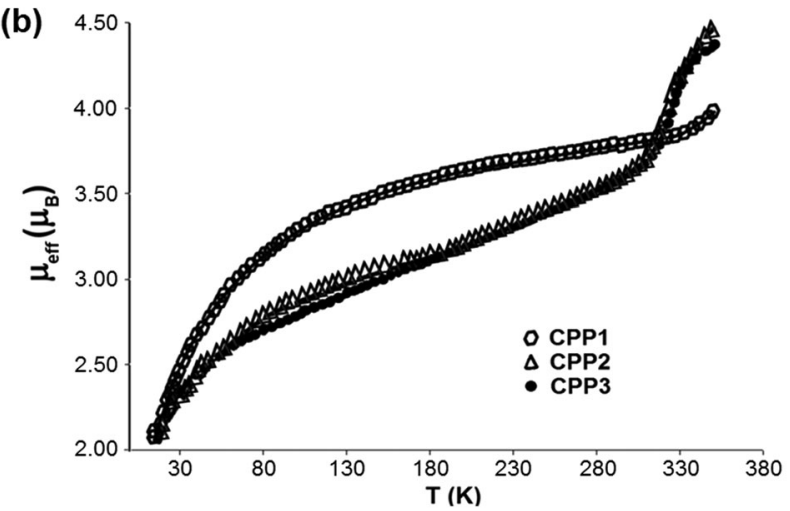

Fig. 5 (a) Schematic of the synthesis of two different hydrophobic CPPs through one-step (I) or two-step (II) approaches. (b) $\mu_{\text {eff values as a }}$ function of temperature for the different amorphous nanoparticles obtained. Figure b extracted from ref. 26

VT complexes is much higher (up to $70 \mathrm{wt} \%$ in some cases), which is relevant for device fabrication purposes.

\subsection{Encapsulation in liquid-filled capsules}

Though successful, we encountered two main limitations for the previously described strategy of physical entrapment of VT complexes within polymeric micro-/nanoparticles (Section 3.2): (I) the VT behaviour of the encapsulated complex was found to be very sensitive to the nature of the polymer used and (II) only very low concentrations of the compound could be encapsulated to prevent aggregation and loss of the switchable behaviour. To overcome these inconveniences, we have recently developed a more universal methodology that relies on the encapsulation of the VT complex into liquid-filled polymeric capsules. ${ }^{29}$ With this aim, polyurea microcapsules filled with a toluene solution of the [Co ${ }^{\text {III }}($ Cat-N-BQ)(Cat-N-SQ)] complex were obtained (Fig. 7). Optical studies revealed solution-like thermochromic behaviour of the filling solution, which mainly displayed ls-Co(III) absorption bands at low temperature $(263 \mathrm{~K})$ and hs-Co(III) absorption bands at high temperature $(363 \mathrm{~K})$. In addition, fine tuning of the thermal VT response was demonstrated by directly replacing the solvent used in the encapsulation process. Finally, this methodology turned to be very simple and versatile as it: (I) uses commercially available reactants for the preparation of the target liquid-filled capsules and (II) does not require the chemical modification of the VT complex of choice.
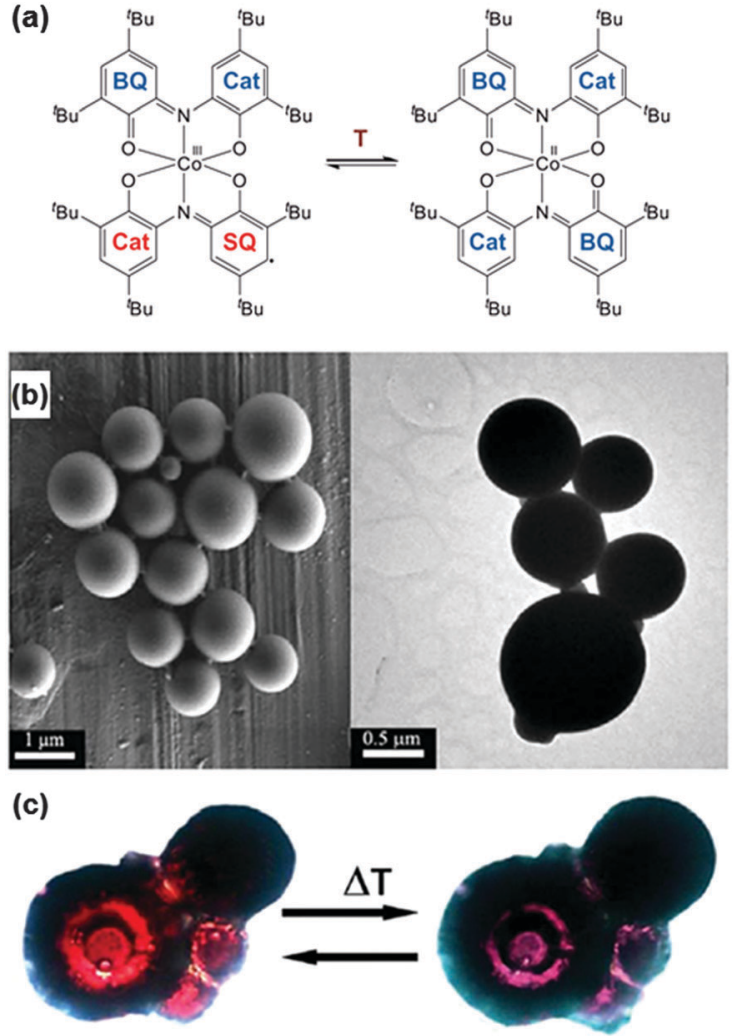

Fig. 6 (a) Thermally-induced electronic interconversion of the VT complex [Co'(Cat-N-BQ)(Cat-N-SQ)]. (b) SEM (left) and TEM (right) images of PMMA particles doped with $2 \mathrm{wt} \%$ of this complex. (c) Temperature induced color change of the encapsulated VT complex in PMMA particles between 300 (left) and 373 (right) followed by optical microscopy. Figures b and c extracted from ref. 28

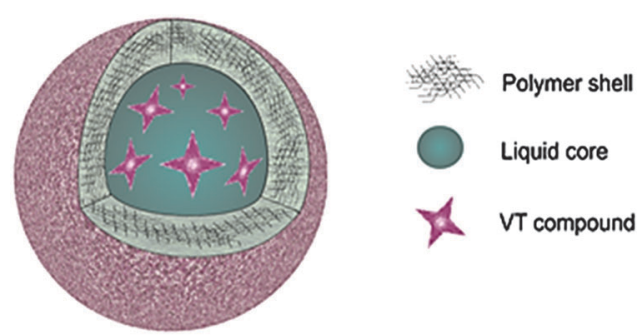

Fig. 7 Polyurea microparticles filled with a solution of the VT complex [Co'l(Cat-N-BQ)(Cat-N-SQ)].

\section{Thin-films}

Dispersion of VT complexes in thin-films has also been recently reported as a successful approach. ${ }^{28}$ The optimisation of the polymeric matrix to successfully transfer the VT behaviour from solution to the solid state was conducted by testing three different complex concentrations ( $2 \mathrm{wt} \%, 4 \mathrm{wt} \%$ and $8 \mathrm{wt} \%)$ in three different polymeric matrices: (I) poly(vinyl alcohol) (PVA), (II) poly(bisphenol) A carbonate (PBC), and (III) poly(methyl methacrylate) (PMMA), well-known polymers of relevant technological interest. In a typical experiment, solutions of the VT-complex $\left[\mathrm{Co}^{\mathrm{III}}(\mathrm{Cat}-\mathrm{N}-\mathrm{BQ})(\right.$ Cat-N-SQ)] and the polymer of choice $(15 \mathrm{wt} \%)$ 
(a)

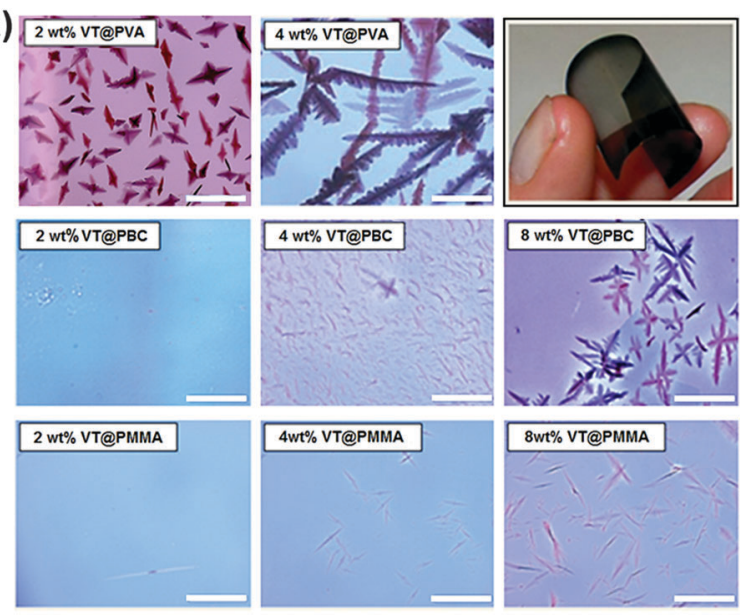

(b)

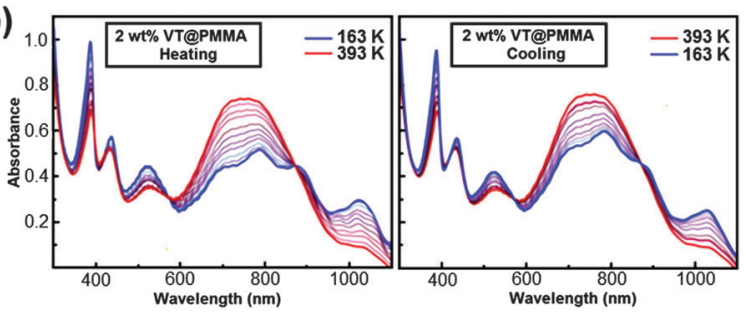

Fig. 8 (a) Drop casting films of PVA, PBC and PMMA containing 2 wt\%, 4 wt\% and 8 wt\% of VT complex [Co'I(Cat-N-BQ)(Cat-N-SQ)]. The topright inset shows an image of a flexible PMMA thin-film containing 2 wt\% of VT complex. (b) Variable-temperature UV-Vis spectra of the thin-film showing the reversible tautomeric effect upon heating and cooling between 163 and 373 K. Adapted from ref. 28.

were deposited onto a glass slide by drop casting, resulting in thin-films of 5-20 micron thickness that could be handled and transferred onto other substrates (Fig. 8a). Afterwards, the occurrence of valence tautomerism was studied by variabletemperature UV-Vis spectroscopy in the 163-393 K temperature range. Best results were obtained for the $2 \mathrm{wt} \%$ PMMA thinfilm, which exhibited a VT interconversion very similar to that found in toluene solution (Fig. 8b). However, an increase of the complex concentration simply from 2 to $4 \mathrm{wt} \%$ resulted in aggregation and crystallisation processes (as confirmed by polarised optical microscopy and X-Ray diffraction), which disrupted the VT behaviour by stabilising the hs-Co(II) isomer over the whole temperature range studied. The rest of the polymers assayed already induced VT aggregation at concentrations as low as $2 \mathrm{wt} \%$, especially in PVA, making the VT-complex thinfilms non-functional.

The tendency to crystallise was also used to convert the volatile behaviour of VT complexes as molecular memories into a permanent effect. When the $2 \mathrm{wt} \%$ PMMA thin-film of the VT complex was heated up to $403 \mathrm{~K}$, just above the polymer $T_{\mathrm{g}}$, and allowed to rapidly cool down to room temperature, the thin-film retained its amorphous character and, therefore, the corresponding reversible switchable behaviour. In contrast, if room temperature was slowly recovered $\left(1 \mathrm{~K} \mathrm{~min}^{-1}\right.$ or less), the crystallisation of the complex took place within the polymeric matrix, as confirmed by optical microscopy. Since crystals of
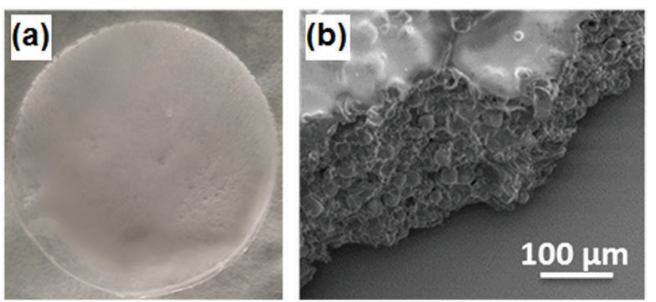

(c)

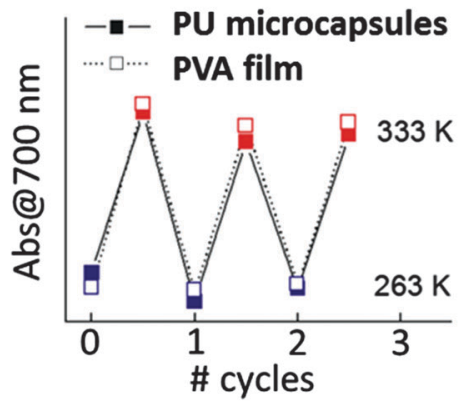

Fig. 9 (a) Photograph of the PVA thin-film prepared from a suspension of polyurea microcapsules containing an oil solution of the VT complex [Co"'(Cat-N-BQ)(Cat-N-SQ)]. (b) SEM image of the edge of a broken piece of the film where the capsules can be observed. (c) Variation of the absorbance at $700 \mathrm{~nm}$ for the VT-containing microcapsules and the corresponding PVA film prepared from them upon application of several cooling-heating cycles from 263 to 333 K. Extracted from ref. 29.

the VT complex were found to be stabilised on its hs-Co(II) form, the characteristics of the high-spin isomer were retained in an irreversible manner upon cooling down to room temperature, and even after the application of several heating/cooling cycles. This represents a new strategy to synchronise VT and phase transition at will by means of the external polymer matrix, without the need for any additional synthetic procedure.

In a further step, we recently reported the fabrication of a PVA composite where the VT complex [C $\left.{ }^{\mathrm{III}}(\mathrm{Cat}-\mathrm{N}-\mathrm{BQ})(\mathrm{Cat}-\mathrm{N}-\mathrm{SQ})\right]$ was introduced as a non-volatile solution in an oil (i.e. Miglyol $^{\mathbb{R}}$ 812) within polyurea (PU) microcapsules. ${ }^{29}$ These films were prepared by simply casting a suspension of the microcapsules dispersed in a PVA-containing water solution (Fig. 9a and b). In this way the VT complex was maintained in a liquid environment and isolated from the polymeric matrix. As a consequence, the final solid VT composite preserved the liquid-like thermochromic behaviour of the VT complex and a reversible change of its spectral properties was observed upon sequential heating and cooling cycles (Fig. 9c), which reproduced that registered for the capsules dispersed in a liquid environment.

\section{Nanostructured surfaces and interfaces}

\subsection{Patterned structures}

5.1.1. Atomic force microscopy (AFM) assisted lithography. In this approach the tip of an AFM is used to deliver ultra-small volumes (femtolitres) of the soluble precursors (inks) to specific areas of a target surface. In a preliminary work, crystals of the well-known metal-organic framework HKUST-1 and spherical 
polyoxometalate nanostructures were grown on precise positions of a surface after the deposition and controlled evaporation of femtolitre-sized droplet solutions of the materials previously synthesised in bulk. ${ }^{30}$ As a follow up of this work, we reported the in situ synthesis of VT coordination polymer particles confined into femtolitre droplet reactors. ${ }^{31}$ For this, we followed two main approaches using the bi-component mixture (ligand and cobalt salt) detailed in Section 3 In the first of these approaches, two consecutive AFM tips of an array were differently functionalised with the ligand (tip 1) and the cobalt salt solutions (tip 2) of interest. Then, the coated tips were used to directly transfer these solutions to the same location of the surface, creating femtolitresized reaction vessels where the coordination reaction occurred. In the second approach, an excess of the inks was loaded on tips 1 and 2, thus forcing them to directly mix on the cantilever array (Fig. 10a-c). The reacting mixture was then immediately transferred to the surface before the precipitation of the coordination polymer material occurred (Fig. 10d). Both approaches turned out to be robust and allow the systematic fabrication of multiple arrays with control over the growth of a single nanoparticle per dot (Fig. 10e-g). In addition, they also enabled control over the size of the grown nanoparticles.

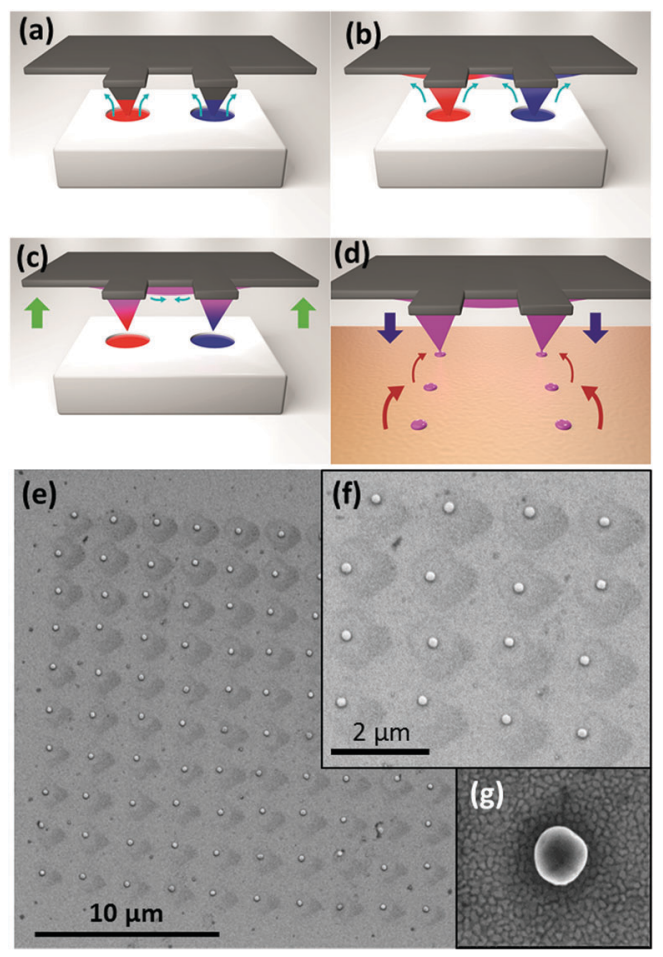

Fig. $10(a-d)$ Schematic representation of one of the procedures used to synthesise CPPs in femtolitre-sized reactors deposited onto a surface. This methodology was based on causing the mixture of two inks containing a metal salt and an organic ligand during the functionalisation of the tips: (a) the tips were first dipped in the inkwells and the inks functionalised each tip; ( $b$ and c) due to capillarity, the inks went up to the cantilevers and mixed; (d) droplets of the reacting mixture of inks were deposited on the surface. (e) $10 \times 10$ particle array obtained by confining the synthesis of CPPs using the procedure described above. (f) Amplification of the same array. (g) A single particle in the array. Adapted from ref. 31.
Alternatively, an AFM tip was also successfully used to deposit PMMA polymer structures doped with the VT complex $\left[\mathrm{Co}^{\mathrm{III}}(\mathrm{Cat}-\mathrm{N}-\mathrm{BQ})(\mathrm{Cat}-\mathrm{N}-\mathrm{SQ})\right]$ on cleaned silicon surfaces by controlling the contact (dwell) time of the PMMA-coated tip with the target surface and the substrate temperature. ${ }^{28}$ Optimised deposition conditions were found for a contact time of $3 \mathrm{~s}$ and a substrate temperature of $443 \mathrm{~K}$, which lies well above the $T_{\mathrm{g}}$ (395 K) of PMMA but below the decomposition temperature of the complex $(478 \mathrm{~K})$. Under these conditions, well defined arrays of dots with a diameter and height of $2.3 \pm 0.1 \mu \mathrm{m}$ and $12 \pm 1 \mathrm{~nm}$, respectively, were obtained by scanning the tip over the surface. A detailed study of the generated structures by AFM revealed that each one of the dots exhibited a fibre-like structure independent of the cooling ramp applied after the deposition process (from 0.2 to $10.0 \mathrm{~K} \mathrm{~min}^{-1}$ ), as shown in Fig. 11. Unfortunately, the VT behaviour of none of the motifs created on surfaces by AFM assisted lithographies could be proven because of the small amount of material deposited, its low magnetic density and the observation of the magnetic transition around room temperature, even though different techniques were used such as surface confined scanning probe techniques, micro-Raman ( $\mu \mathrm{RS})$ spectroscopy and X-ray photoelectron spectroscopy (XPS).

5.1.2. Nanoimprint lithography (NIL). This lithographic technique was also successfully used to pattern VT complexes entrapped in a polymeric matrix. ${ }^{28}$ In a typical experiment, a solution of [Co ${ }^{\mathrm{III}}$ (Cat-N-BQ)(Cat-N-SQ) $]$ and PMMA with a similar ratio to that used for the fabrication of thin-films (see Section 4) was spin-coated on a silicon surface heated above the $T_{\mathrm{g}}$ of PMMA and, immediately after that, a stamp was brought into contact under pressure. A reactive ion etching process was

(a)

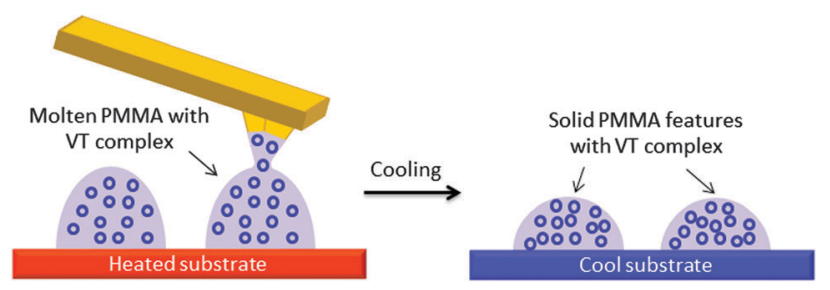

(b)

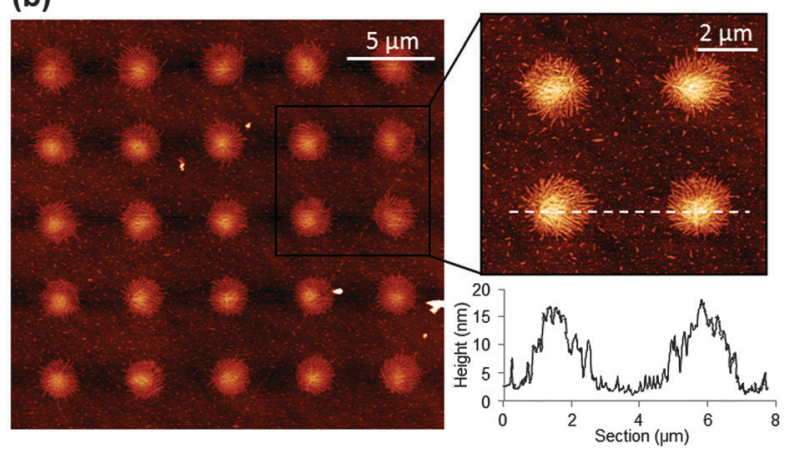

Fig. 11 (a) Schematic representation of the deposition of VT-doped PMMA patterns. (b) AFM topography images of a $5 \times 5$ dot-like feature array and the corresponding height profile. Extracted from ref. 28. 
(a)

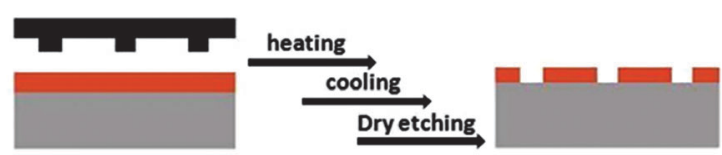

(b)

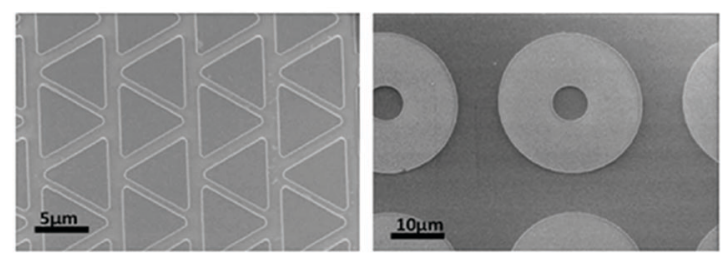

(c)

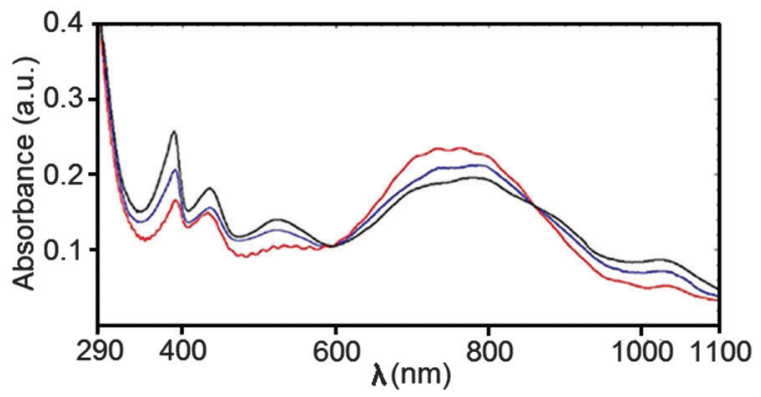

Fig. 12 (a) Schematic representation of the NIL process used for the fabrication of the VT polymeric structures over a thin-film obtained by spin coating of a PMMA-containing solution of [Co ${ }^{\text {III }}(\mathrm{Cat}-\mathrm{N}-\mathrm{BQ})(\mathrm{Cat}-\mathrm{N}$ $S Q)]$. (b) SEM images of selected triangular and doughnut-like motifs. (c) Variable temperature electronic spectra of a nanostructured PMMA thin-film containing 2 wt\% of VT complex. Colour code: $193 \mathrm{~K}$ (black), $298 \mathrm{~K}$ (blue) and $353 \mathrm{~K}$ (red). Extracted from ref. 28

finally used to transfer the pattern in resistance to the underneath substrate (Fig. 12a). Afterwards, the system was cooled down as fast as possible to avoid VT crystallisation, while the mold was separated from the sample resulting in a negative replica of the stamp on the film. Optical and electron microscopies showed the formation of patterned motifs with different shapes, ranging from squares to circles or lines, with dimensions close to $1 \mu \mathrm{m}$ (Fig. 12b). More interestingly, variable-temperature diffuse reflectance UV-Vis spectra of a silicon oxide piece covered with NIL patterned films showed that the printed motifs retained the switchable VT behaviour. Typical bands for the ls-Co(III) isomer were observed in the low-temperature regime that decreased in intensity as the temperature raised, whereas the characteristic bands for the hs-Co(II) isomer increased in intensity (Fig. 12c). This behaviour is reminiscent of the interconverting properties shown by the same complex in solution and bulk polymeric thin-films.

\subsection{Self-assembled monolayers}

5.2.1. SAMs of VT molecular systems. Self-assembled monolayers (SAMs) represent an easy and straightforward way to functionalise surfaces with different functionalities. Moreover, they are formed under mild conditions and in general have good stability. ${ }^{32}$

Pioneering work on the introduction of VT complexes in SAMs was performed by Shultz et al., who described the preparation of $2 \mathrm{~nm}$ diameter gold clusters decorated with a monolayer of a cobalt bis(dioxolene) VT compound. ${ }^{33}$ For that, they obtained gold clusters functionalised with a bipyridine thiol derivative to which they added the cobalt bis(dioxolene) fragment to generate the surface-bound complex. The authors reported significant differences in the thermodynamics of the VT process of the surface-immobilised complex compared to the free model compound. They attributed these differences to the smaller accessible area for the solvent caused by surface confinement as well as to molecular close packing, and suggested that this effect could be used to tune valence tautomerism.

More recently, the control of the charge distribution of VT complexes assembled on flat gold surfaces has been attained by Poneti and co-workers. ${ }^{34}$ In this case, the authors synthesised a series of catechol-based VT complexes with different charge distributions of the ls-Co(III)Cat and the hs-Co(II)SQ tautomers and assembled them on gold surfaces through the thiol moiety previously introduced in the catechol ligand. In contrast to the results reported by Shultz et al., these authors observed that the charge distribution of the complexes as well as their entropydriven interconversion equilibria were not affected by surface grafting and that the VT behaviour of the bulk phase was quantitatively reproduced on the surface. An important issue that was not addressed in any of these previous reports is the density of integration. This should be of paramount importance for the performance of future switchable material-based devices and could represent an obstacle for their final application.

In this direction, we recently reported the interfacial properties of a SAM bearing outward-facing catechol moieties on different gold surfaces. ${ }^{35}$ The results obtained in these experiments proved that the adhesive character of the catechol unit was retained in a reproducible way once it was assembled on the surface. Also, the chelating ability of the aromatic ring was maintained, which was demonstrated by assembling magnetic nanoparticles over the catechol-terminated monolayer. Besides these encouraging results, we also found that the presence of the catechol moiety as a head group hampered the formation of a high quality monolayer of tightly packed molecules. Additionally, this resulted in the formation of poor quality sub-monolayers fabricated by lithographic methods or as stabilising layers of gold nanoparticles. No follow-up on the use of these catechol-based SAMs for the fabrication of VT monolayers has been reported so far.

5.2.2. SAMs of VT-CPP nanoparticles. Recently, we described an alternative approach for the organisation of VT-active compounds on surfaces based on the anchoring of VT-CPPs (described in Section 3) to a suitably functionalised surface. ${ }^{36}$ For this, VT-CPPs bearing free carboxylic acid groups on their surface ( $\sim 130 \mathrm{~nm}$ in diameter) were obtained upon combination of the polymerising ligand bix with the electroactive $\mathrm{Co}\left(3,5\right.$-dhcSQ)(3,5-dhcCat) units, where 3,5-dhcSQ ${ }^{-}$and 3,5$\mathrm{dhcCat}^{2-}$ are the semiquinonate radical and catecholate forms of 3,4-dihydroxycinnamic acid (dhc), respectively (Fig. 13a). Then, the carboxylic acid moieties located at the surface of the CPPs were bonded to an amino-terminated SAM on gold through a simple carbodiimide-mediated amide coupling reaction (Fig. 13b). This process resulted in the formation of a monolayer 
(a)

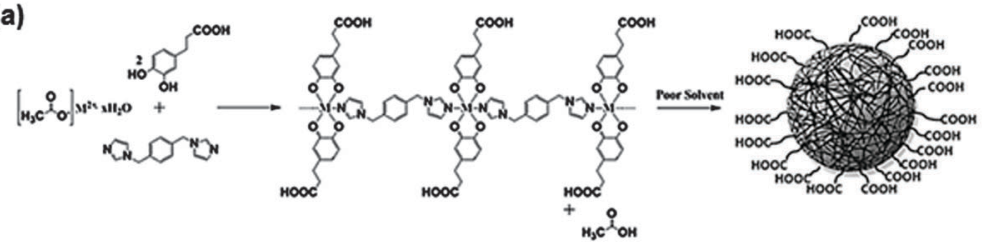

(b)

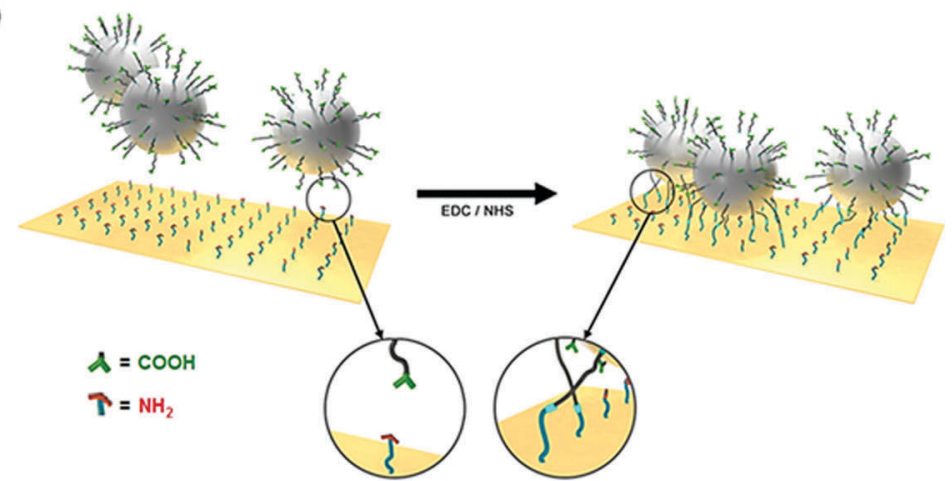

(c)

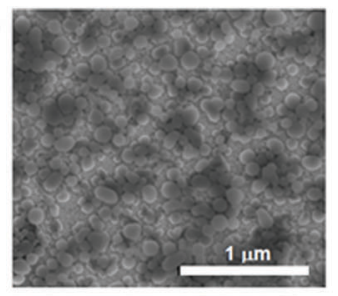

(d)

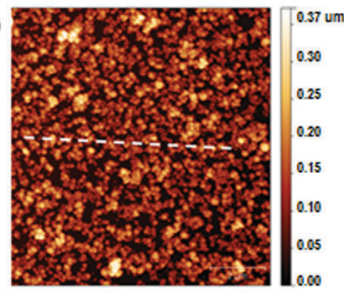

(e)

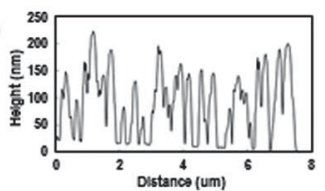

Fig. 13 (a) Schematic of the formation of cobalt-based VT-CPPs whose surface is decorated with carboxylic acid groups. (b) Schematic of the attachment of these nanoparticles onto a gold surface previously covered with a monolayer of amino-terminated alkyl chains through a carbodiimidemediated coupling reaction. (c) SEM image of the VT-CPPs monolayer on gold. (d) AFM image of the CPPs attached to the surface. (e) Height profile of the nanoparticle monolayer attached on the surface. Extracted from ref. 36.

of VT-CPPs covalently attached to the gold surface with excellent coverage (85-90\%). Finally, the VT behaviour of the nanoparticles upon surface immobilisation was studied and confirmed by XPS experiments.

\section{Conclusions}

So far great advances have already been made for obtaining functional valence tautomeric systems at the micro-/nanoscale. For instance, different families of nanoparticles with diverse loading amounts of VT complex, small hysteresis effects or control over their magnetic properties have been reported. However, even though amazing results of interconverting capabilities and potential applications have been reported, the promise of a functional switching molecular device working at the micro-/nanoscale and at room temperature has not been completely materialized yet, and it still remains a subject of continuous interest. In the light of these results, it seems quite clear to us that more research needs to be done aiming at the integration of all the micro-/nanostructures previously described on truly operational devices. But even if this final goal cannot be eventually achieved, it is worth mentioning that most of the structuration approaches described in this review could be easily translated or would be of relevance for the integration of other molecular materials in functional devices.

\section{Acknowledgements}

N. A. V.-M. thanks the Ministerio de Ciencia e Innovación (MICINN) for a predoctoral FPU fellowship. M. G. thanks the CSIC for a predoctoral grant (JAEpre). C. B. thanks the ICN2 and the Severo Ochoa program for his predoctoral grant. This work was supported by projects MAT2015-70615-R and CTQ2015-65439-R from the Spanish Government and by FEDER funds. ICN2 acknowledges support from the Severo Ochoa Program (MINECO, Grant SEV-2013-0295).

\section{Notes and references}

1 C. K. Jørgensen, Coord. Chem. Rev., 1966, 1, 164.

2 E. Evangelio and D. Ruiz-Molina, Eur. J. Inorg. Chem., 2005, 2957.

3 (a) W. Kaim, Inorg. Chem., 2011, 50, 9752; (b) O. Sato, J. Tao and Y. Z. Zhang, Angew. Chem., Int. Ed., 2007, 46, 2152; (c) A. Dei, D. Gatteschi, C. Sangregorio and L. Sorace, Acc. Chem. Res., 2004, 37, 827.

4 (a) D. Gentili, F. Valle, C. Albonetti, F. Liscio and M. Cavallini, Acc. Chem. Res., 2014, 47, 2692; (b) D. A. Shultz and M. L. Kirk, Chem. Commun., 2014, 50, 7401; (c) N. Domingo, E. Bellido and D. Ruiz-Molina, Chem. Soc. Rev., 2012, 41(1), 258; (d) A. Calzolari, Y. Chen, G. F. Lewis, D. B. Dougherty, D. Shultz and M. B. Nardelli, J. Phys. Chem. B, 2012, 116, 13141; (e) M. Cavallini, I. Bergenti, S. Milita, G. Ruani, I. Salitros, Z.-R. Qu, R. Chandrasekar and M. Ruben, Angew. Chem., Int. Ed., 2008, 47, 8596; ( $f$ ) K. Szaciłowski, Chem. Rev., 2008, 108, 3481.

5 R. M. Buchanan and C. G. Pierpont, J. Am. Chem. Soc., 1980, 102, 4951.

6 (a) A. Dei and D. Gatteschi, Angew. Chem., Int. Ed., 2011, 50, 11852; (b) C. G. Pierpont, Coord. Chem. Rev., 2001, 216-217, 99. 
7 (a) V. I. Minkin, A. A. Starikova and A. G. Starikov, Dalton Trans., 2015, 44, 1982; (b) J. Chen, E. Wuttke, W. Polit, Th. Exner and R. F. Winter, J. Am. Chem. Soc., 2013, 135, 3391; (c) J. Guasch, L. Grisanti, S. Jung, D. Morales, G. D'Avino, M. Souto, X. Fontrodona, A. Painelli, F. Renz, I. Ratera and J. Veciana, Chem. Mater., 2013, 25, 808; (d) C. Boskovic, in Spin-Crossover Materials: Properties and Applications, ed. M. A. Halcrow, John Wiley \& Sons Ltd, Oxford, UK, 2013, ch. 7.

8 (a) K. G. Alley, G. Poneti, P. S. D. Robinson, A. Nafady, B. Moubaraki, J. B. Aitken, S. C. Drew, Ch. Ritchie, B. F. Abrahams, R. K. Hocking, K. S. Murray, A. M. Bond, H. H. Harris, L. Sorace and C. Boskovic, J. Am. Chem. Soc., 2013, 135, 8304; (b) B. Li, L.-Q. Chen, J. Tao, R.-B. Huang and L.-S. Zheng, Inorg. Chem., 2013, 52, 4136; (c) A. Dei and L. Sorace, Appl. Magn. Reson., 2010, 38, 139; (d) A. I. Poddel'sky, V. K. Cherkasov and G. A. Abakumov, Coord. Chem. Rev., 2009, 253, 291; (e) A. Beni, A. Dei, S. Laschi, M. Rizzitano and L. Sorace, Chem. - Eur. J., 2008, 14, 1804.

9 (a) X.-Y. Chen, R.-J. Wei, L.-S. Zheng and J. Tao, Inorg. Chem., 2014, 53, 13212; (b) A. Panja, RSC Adv., 2013, 3, 4954; (c) H. Ohtsu and K. Tanaka, Angew. Chem., Int. Ed., 2004, 43, 6301; (d) D. M. Adams and D. N. Hendrickson, J. Am. Chem. Soc., 1996, 118, 11515.

10 (a) P. Leeladee, R. A. Baglia, K. A. Prokop, R. Latifi, S. P. de Visser and D. P. Goldberg, J. Am. Chem. Soc., 2012, 134, 10397; (b) M. Kondo, M. Uchikawa, K. Namiki, W.-W. Zhang, Sh. Kume, E. Nishibori, H. Suwa, Sh. Aoyagi, M. Sakata, M. Murata, Y. Kobayashi and H. Nishihara, J. Am. Chem. Soc., 2009, 131, 12112; (c) Y. Yoshida, H. Tanaka, G. Saito, L. Ouahab, H. Yoshida and N. Sato, Inorg. Chem., 2009, 48, 9989; (d) A. Caneschi, A. Dei, F. Fabrizi De Biani, P. Gütlich, V. Ksenofontov, G. Levchenko, A. Hoefer and F. Renz, Chem. - Eur. J., 2001, 7, 3926.

11 T. Tezgerevska, K. G. Alley and C. Boskovic, Coord. Chem. Rev., 2014, 268, 23.

12 (a) J. Hasserodt, J. L. Kolanowski and F. Touti, Angew. Chem., Int. Ed., 2014, 53, 60; (b) C. Cervetti, E. Heintze and L. Bogani, Dalton Trans., 2014, 43, 4220; (c) Y. Mulyana, G. Poneti, B. Moubaraki, K. S. Murray, B. F. Abrahams, L. Sorace and C. Boskovic, Dalton Trans., 2010, 39, 4757; (d) W. Hong, S. Lee, H. Lee, T. Hwan Noh, Y.-A. Lee and O.-S. Jung, Transition Met. Chem., 2012, 37, 563; (e) O. Cador, A. Dei and C. Sangregorio, Chem. Commun., 2004, 652.

13 E. Evangelio, M.-L. Bonnet, M. Cabañas, M. Nakano, J.-P. Sutter, A. Dei, V. Robert and D. Ruiz-Molina, Chem. - Eur. J., 2010, 16, 6666.

14 D. Ruiz-Molina, J. Veciana, K. Wurst, D. N. Hendrickson and C. Rovira, Inorg. Chem., 2000, 39, 617.

15 R. D. Schmidt, D. A. Shultz, J. D. Martin and P. D. Boyle, J. Am. Chem. Soc., 2010, 132, 6261.

16 F. Novio, J. Campo and D. Ruiz-Molina, Inorg. Chem., 2014, 53, 8742 .
17 (a) E. Evangelio, C. Rodriguez-Blanco, Y. Coppel, D. N. Hendrickson, J. P. Sutter, J. Campo and D. Ruiz-Molina, Solid State Sci., 2009, 11, 793; (b) E. Evangelio and D. RuizMolina, C. R. Chim., 2008, 11, 1137.

18 (a) A. Bencini, A. Caneschi, C. Carbonera, A. Dei, D. Gatteschi, R. Righini, C. Sangregorio and J. Van Slageren, J. Mol. Struct., 2003, 656, 141; (b) D. M. Adams, A. Dei, A. L. Rheingold and D. N. Hendrickson, J. Am. Chem. Soc., 1993, 115, 8221.

19 (a) D. Kiriya, K. Nakamura, S. Kitagawa and H.-Ch. Chang, Chem. Commun., 2010, 46, 3729; (b) D. Kiriya, H.-Ch. Chang, K. Nakamura, D. Tanaka, K. Yoneda and S. Kitagawa, Chem. Mater., 2009, 21, 1980; (c) D. Kiriya, H.-Ch. Chang and S. Kitagawa, J. Am. Chem. Soc., 2008, 130, 5515.

20 M. Oh and C. A. Mirkin, Nature, 2005, 438, 651.

21 I. Imaz, D. Maspoch, C. Rodríguez-Blanco, J. M. PérezFalcón, J. Campo and D. Ruiz-Molina, Angew. Chem., Int. Ed., 2008, 47, 1857.

22 M. Guardingo, F. Busqué, F. Novio and D. Ruiz-Molina, Inorg. Chem., 2015, 54, 6776.

23 F. Nador, F. Novio and D. Ruiz-Molina, Chem. Commun., 2014, 50, 14570.

24 L. Amorín-Ferré, F. Busqué, J. L. Bourdelande, D. Ruiz-Molina, J. Hernando and F. Novio, Chem. - Eur. J., 2013, 19, 17508.

25 (a) F. Novio, J. Lorenzo, F. Nador, K. Wnuk and D. Ruiz-Molina, Chem. - Eur. J., 2014, 20, 15443; (b) I. Imaz, M. Rubio-Martínez, L. García-Fernández, F. García, D. Ruiz-Molina, J. Hernando, V. Puntes and D. Maspoch, Chem. Commun., 2010, 46, 4737; (c) I. Imaz, J. Hernando, D. Ruiz-Molina and D. Maspoch, Angew. Chem., Int. Ed., 2009, 48, 2325.

26 F. Novio and D. Ruiz-Molina, RSC Adv., 2014, 4, 15293.

27 A. Caneschi, A. Cornia and A. Dei, Inorg. Chem., 1998, 37, 3419.

28 F. Novio, E. Evangelio, N. Vazquez-Mera, P. González-Monje, E. Bellido, S. Mendes, N. Kehagias and D. Ruiz-Molina, Sci. Rep., 2013, 3, 1708.

29 N. A. Vázquez-Mera, C. Roscini, J. Hernando and D. RuizMolina, Adv. Funct. Mater., 2015, 25, 4129.

30 E. Bellido, S. Cardona-Serra, E. Coronado and D. RuizMolina, Chem. Commun., 2011, 47, 5175.

31 M. Guardingo, P. González-Monje, F. Novio, E. Bellido, F. Busqué, G. Molnár, A. Bousseksou and D. Ruiz-Molina, ACS Nano, 2016, 10, 3206.

32 A. Ullman, Chem. Rev., 1996, 96, 1533.

33 S. Bin-Salamon, S. Brewer, S. Franzen, D. L. Feldheim, S. Lappi and D. A. Shultz, J. Am. Chem. Soc., 2005, 127, 5328. 34 G. Poneti, L. Poggini, M. Mannini, B. Cortigiani, L. Sorace, E. Otero, Ph. Sainctavit, A. Magnani, R. Sessoli and A. Dei, Chem. Sci., 2015, 6, 2268-2274.

35 M. Guardingo, E. Bellido, R. Miralles-Llumà, J. Faraudo, J. Sedó, S. Tatay, A. Verdaguer, F. Busqué and D. Ruiz-Molina, Small, 2014, 10, 1594.

36 P. González-Monje, F. Novio and D. Ruiz-Molina, Chem. - Eur. J., 2015, 21, 10094. 